1 Universidade Federal do Rio Grande do Sul (UFRGS) - Porto Alegre (RS), Brasil. alcides.miranda@ufrgs.br

\section{A focalização utilitária da Atenção Primária à Saúde em viés tecnocrático e disruptivo}

\author{
The utilitarian focusing of Primary Health Care in technocratic and \\ disruptive bias
}

Alcides Silva de Miranda1

DOI: 10.1590/0103-1104202012720

\begin{abstract}
RESUMO Ensaio argumentativo acerca do sentido contextual, dos condicionantes conjunturais e dos indicativos estratégicos constantes no Programa Previne Brasil, que estabelece nova logística e modalidade de financiamento e adscrição para a atenção primária do Sistema Único de Saúde (SUS). Destaca-se contextualmente a hegemonia neoliberal, com tendência para a colonização subserviente de governos e políticas públicas. Conjunturalmente, o alinhamento disruptivo do governo Bolsonaro, permeado por ofensivas ultraliberais, pendores impositivos e práticas autoritárias. Em afinidade e derivação concomitante, a referida estratégia programática tende a consubstanciar uma nova forma de focalização para demandas estratificadas e de segmentação para coberturas e serviços de saúde estando regida por racionalidade tecnocrática e utilitária, que tende a desconstituir os preceitos e as diretrizes estratégicas constitucionais das políticas públicas de saúde. Caracteriza-se principalmente por: capitação e per capitalização de demandas 'administráveis', nos termos de 'governança clínica' regulada por política econômica de austeridade e contingenciamento de gastos sociais; deslocamento do modo de adscrição territorial e populacional com responsabilização de equipes multiprofissionais visando à Atenção Integral à Saúde, para outro modo de adscrição individualizada, focalizada e estratificada de clientelas; aplicabilidade descontextualizada do SUS, para critérios e logísticas de ponderação alocativa de recursos financeiros de custeio e de pagamento compensatório ao 'desempenho' do trabalho de equipes.
\end{abstract}

PALAVRAS-CHAVE Atenção Primária à Saúde. Estratégia Saúde da Família. Política de saúde. Financiamento da assistência à saúde. Sistema Único de Saúde.

ABSTRACT An essay about the contextual meaning, the conjunctural conditioning and the strategic indicatives within the Prevent Brazil Programme, which establishes a new logistics and funding modality for primary care in the Brazilian Unified Health System. It contextually highlights the neoliberal hegemony, with a tendency towards a subservient colonization of governments and public policies and in conjuncture, the disruptive alignment of the Bolsonaro administration, permeated by ultraliberal offensives, imposing biases and authoritarian practices. In concomitant derivation, this programmatic strategy tends to substantiate a new form of targeting for stratified demands and segmentation for hedges and health services. Being governed by a technocratic and utilitarian rationality, which tends to disregard the precepts and constitutional strategic guidelines of public health policies. It is characterized mainly by: capitation and per capitalization of 'manageable' demands, in terms of 'clinical governance' regulated by austerity economic policy and social spending contingency; displacement of the territorial and population mode of enrollment with the accountability of multiprofessional teams aiming at Integral Health Care, to another individualized, focused and stratified mode of clientele; decontextualized applicability of the health system, with criteria and logistics of allocative weighting of financial resources of cost and compensatory payment to the 'performance' of team work.

KEYWORDS Primary Health Care. Family Health Strategy. Health policy. Healthcare financing. Unified Health System. 


\section{Introdução}

Argumenta-se, no presente texto, que o sentido e os termos de financiamento estabelecidos para a Atenção Primária à Saúde do Sistema Único de Saúde (APS-SUS), constantes no 'Programa Previne Brasil' (Portaria MS no 2.979/2019)' 1 , consubstanciam uma nova lógica simbólica e modalidade de focalização para recursos e políticas públicas de saúde. Uma modalidade de focalização regida por racionalidade instrumental e utilitarista, que induz a desconstituição do preceito de integralidade das políticas públicas de saúde, caracterizando-se por: capitação e per capitalização de demandas 'evidenciadas', 'reconhecidas' e 'estratificadas' em racionalidade de 'governança clínica' de viés utilitário e tecnocrático, regulada por estratégia de contingenciamento de gastos governamentais 'primários'; deslocamento do modo de adscrição territorial e populacional da responsabilidade de equipes multiprofissionais e interdisciplinares pela Atenção Integral à Saúde para outro modo de adscrição programática de clientelas padronizáveis e administráveis em termos de coberturas segmentadas; deslocamento de um critério logístico de ponderação alocativa para recursos financeiros de custeio entre contextos sociais substancialmente diversos (Norte/Sul); dimensionamento e valorização compensatória do 'desempenho' de trabalho profissional a partir de comportamentos regrados por tal racionalidade instrumental.

Como a nova modalidade de financiamento para a APS-SUS encontra-se provida de racionalidade instrumental com pretensões normativas, embalada em discurso tecnocrático de entorno setorial, torna-se necessária a sua contextualização, como também a projeção de seu alinhamento em uma conjuntura política primada em pendores autoritários, em práticas impositivas e disruptivas de governo. Eis, porque, antes de versar e argumentar especificamente sobre tal assunto específico, convém discorrer brevemente sobre uma sumária contextualização acerca do tema da focalização de políticas sociais na contemporaneidade e o seu sentido precípuo de racionalidade utilitária.

A ênfase no presente artigo tem a ver com a tematização sobre discursos práticos ${ }^{2}$ dos dirigentes governamentais acerca da mudança estratégica institucional (administrativa e programática) para a APS no Brasil, pelos quais esses governantes buscam justificar as suas proposições normativas e os seus proferimentos regulativos, em razão de sua aplicabilidade nos sistemas institucionalizados de ações. Dessa forma, não se busca tematizar aspectos práticos e específicos, decorrentes ou derivados das eventuais mudanças.

\section{De concepções, justificativas e premissas contextuais acerca das estratégias governamentais de focalização para as políticas sociais}

Em se tratando de recursos públicos aplicados e utilizados em políticas sociais, desde muitas décadas persiste o debate e as reciclagens de iniciativas governamentais que contrapõem dialeticamente a concepção utilitária de sua focalização em determinados grupos populacionais ('denominadores populacionais' de miséria, de riscos, de vulnerabilidades etc.) e a concepção valorativa (ethos social) da (re) produção de melhor equidade redistributiva. Evidentemente, tais concepções derivam de distintos princípios, valores, interesses, justificativas e propósitos políticos, decorrendo também em distintas estratégias institucionais (administrativas, programáticas) para a alocação prioritária de recursos orçamentários governamentais e para disponibilização e acessibilidade de sistemas institucionalizados e de serviços públicos.

Muitas vezes, as estratégias governamentais de focalização e de equidade redistributiva (ou, pelo menos, do enfrentamento de iniquidades) tendem a ocorrer de forma justaposta 
ou combinada, dificultando ainda mais os discernimentos entre elas. Em geral, o que se pode realçar casuisticamente é o sentido predominante dessas concepções e disposições estratégicas no conjunto de determinadas políticas governamentais. O que se pode realçar conjunturalmente e contextualmente são as interveniências mais abrangentes no plano internacional e em perspectiva tendencial.

É difícil e complexa a distinção classificatória entre os termos de focalização e de produção de equidades (ou confronto de iniquidades) ${ }^{3}$ para políticas sociais, uma vez que a preponderância de uns ou de outros depende não somente do propósito ou do escopo de estratégias institucionais e setoriais em intercurso, mas, sobretudo, dos contextos históricos, sociais e políticos em que ocorrem. Dependendo do contexto histórico e social, uma mesma estratégia governamental pode tender, concomitante, ao sentido de focalização e/ou de produção de equidades sociais. Por exemplo, em um contexto social de menor concentração e de melhor distribuição de renda, de menos injustiças sociais, uma determinada estratégia governamental tipicamente focalizada também poderia diminuir iniquidades ou produzir equidades mais abrangentes (de acesso, de utilização de serviços, de impactos etc.) e transcendentes; enquanto, em um contexto em condição inversa, a mesma iniciativa de focalização dificilmente iria além da estratificação compensatória com perpetuação de dependência e com o incremento do controle estatal sobre indivíduos e grupos populacionais.

Abundam argumentos justificativos e propositivos para ambas as perspectivas, focalização ou equidade redistributiva, que perduram e são incrementalmente refinados desde décadas. Também há estratégias institucionais e modalidades organizativas em ambas as perspectivas, que constituem reciclagens e instituem mudanças decorrentes de novos contextos históricos, políticos, econômicos e societários.

Em termos de platitudes de racionalização instrumental para a focalização de recursos e gastos governamentais, persiste um discurso justificativo que alega a inevitável insuficiência de fundos orçamentários públicos para o provimento de políticas sociais, principalmente em função de uma reprodução progressiva e dos infindáveis desdobramentos de suas demandas ('ofertas satisfeitas induzem e derivam novas demandas'), além da disseminada noção de 'incompetência estatal' para um gerenciamento 'eficiente' e da consequente exigência de 'sobrecarga tributária'. Todavia, amparando tal 'discurso prático', há uma concepção primordial e secular acerca das funções e responsabilidades do Estado, na qual se advoga que as políticas sociais deveriam estar focalizadas somente naqueles indivíduos e grupos incapazes de vender até mesmo a sua força de trabalho e, portanto, desprovidos de competência meritocrática e de condições objetivas para atender às próprias necessidades e demandas essenciais, adquirindo bens e serviços nos mercados. Políticas sociais de baixo custo orçamentário focalizado em excluídos das sociedades de mercados, sem maiores exigências tributárias aos 'empreendedores' e aos consumidores com competência meritocrática.

Mesmo os discursos práticos e justificativos acerca de focalizações para políticas sociais, mesmo as seculares premissas do liberalismo econômico (direito à propriedade, 'livre' iniciativa, 'livre' concorrência, competência meritocrática, sociedades mercantis 'autorreguladas', 'Estado mínimo' não intervencionista etc.) ${ }^{4}$, não prescindiram do amparo em justificativas morais com pretensões éticas. Na modernidade histórica, o surgimento, o desenvolvimento e a hegemonia (inicialmente ocidental) da filosofia moral do 'utilitarismo' (Bentham, Stuart Mill e outros menos citados) ${ }^{5}$ vão consubstanciar um sentido paradoxal para justificar os termos de 'eficiência' institucional, inclusive do Estado e de suas políticas públicas, uma razão instrumental, teleológica ${ }^{6}$, que se sobrepõe a quaisquer (pre)tensões normativas apriorísticas e derivadas de valores éticos sociais. Grosso modo, ao pendor 'utilitarista', importa mais os resultados práticos das intervenções políticas 
do que as suas pretensões éticas ou morais, suas tensões constitucionais e normativas.

A ênfase nos termos de racionalização justificativa para determinadas disposições políticas se torna importante porque eles tendem a circunscrever um horizonte hermenêutico doutrinal, um continente normativo e discursivo para comportamentos regrados e, também, perspectivas para intervenções governamentais. Michel Foucault cunhou o termo 'governamentalidade' para definir os tipos de racionalidades estruturantes para as ações governantes e para a introjeção de comportamentos regrados de (auto)governados ${ }^{7,8}$.

Nos primeiros 70 anos do século XX, o sentido primordial de governamentalidade 'utilitarista' concernente às políticas liberais de Estados e de governos era movido pelo afã de 'desenvolvimento econômico' baseado no capital produtivo decorrente da industrialização em âmbito urbano. A ideologia hegemônica era de que os meios e modos de desenvolvimento econômico industrial decorreriam em desenvolvimento social, portanto, as políticas sociais deveriam ser dependentes, acessórias e sinérgicas a tal sentido. Nas sociedades industrializadas, as estratégias de focalização de políticas sociais estavam orientadas para os estratos referidos anteriormente: daqueles sem competência meritocrática e excluídos das possibilidades de consumo mercantil (populações abaixo da 'linha da pobreza', idosos 'sem previdência’ etc). Nas sociedades pré-industrializadas ou em processo de industrialização 'multinacional' para a produção e o consumo domésticos, caso do Brasil, as estratégias de focalização de políticas sociais visavam ao contingenciamento de gastos públicos como lastro para garantir o pagamento regular dos endividamentos externos e diminuição da carga tributária dos setores produtivos. Diversas estratégias institucionais de focalização e tecnologias correlatas de planejamento e programação foram desenvolvidas, e houve grande investimento para o adestramento afim das tecnoburocracias estatais do então chamado 'terceiro mundo'?
Para os países industrializados do Hemisfério Norte Ocidental, no que se refere, especificamente, às políticas sociais de proteção ou seguridade social e, particularmente, saúde, as estratégias de focalização poderiam ser caracterizadas como de excepcionalidades: os típicos 'denominadores populacionais' de incompetência meritocrática. Para os países periféricos não industrializados ou semi-industrializados, as estratégias de focalização estavam orientadas para denominadores populacionais de risco (social, epidemiológico) e para determinadas condições crônicas com magnitude e transcendência em termos de impactos econômicos diretos e indiretos (absenteísmo, gastos previdenciários com pensões etc.) ${ }^{\mathbf{1 0}, 11}$.

A partir da década de 1980, o sentido 'utilitário’ para a focalização das políticas sociais de Estados foi deslocado para a órbita do 'capital improdutivo'12, principalmente em seu apêndice parasitário de orçamentos públicos. $\mathrm{O}$ chamado 'mercado financeiro', dependente de agiotagens, especulações, apostas e jogos rentistas, existe desde os primórdios da história humana; mas, a partir da década de 1980, obteve protagonismo, preponderância e hegemonia em termos de direcionalidade política e 'governança' global. O imperativo de contingenciamento de gastos sociais nos orçamentos governamentais passou a servir de lastro, em menor medida, para o pagamento de dívidas externas originárias de ciclos 'desenvolvimentistas' e, em maior medida, para pagar as espirais de juros de 'dívidas públicas', expressão genérica para definir agiotagem sistêmica de orçamentos públicos ${ }^{\mathbf{1 2}}$.

Ao mesmo tempo, foi incrementada e disseminada uma ofensiva ideológica de preconceitos sobre a incompetência gerencial do Estado para com os denominados 'gastos primários' e a inviabilidade da administração pública direta.

Além das estratégias de focalização de políticas sociais, as alternativas apresentadas para um melhor 'gerenciamento' de recursos orçamentários têm visado ao empresariamento das principais atividades e serviços 
dos estabelecimentos estatais (mudança de institucionalidade da administração direta para a administração indireta sob a égide do direito privado, com introjeção de racionalidade empresarial) e ao seu agenciamento por intermédio de associações privadas de caráter ambivalente: 'público não estatal' e de 'quase-mercado' (como as Organizações Sociais e congêneres). Para o gerenciamento e a prestação de serviços auxiliares e de apoio às instituições públicas, é preconizada a contratação colateralizada de terceiros (terceirização e suas derivações). Ainda, para a contenção do chamado deficit primário, é preconizada a privatização de empresas estatais de mercado, com atividades econômicas e serviços considerados lucrativos ${ }^{\mathbf{1 3}}$.

O Banco Mundial e o Fundo Monetário Internacional (FMI) têm sido as principais instâncias para veiculação e imposição de 'receituários' de 'ajuste fiscal' em termos de políticas governamentais (no continente europeu, o FMI alinhou-se ao Banco Central Europeu e à Comissão Europeia, formando a chamada Troika, com a mesma finalidade), como também, especificamente, para a consubstanciação tecnocrática de estratégias institucionais de focalização para políticas sociais ${ }^{\mathbf{1 2}, 14-16}$.

Ao longo das últimas décadas, e geralmente, os receituários para focalizações de políticas sociais têm-se modificado muito pouco, uma vez que, embora a destinação dos desvios de recursos públicos tenha se deslocado para o capital improdutivo, os propósitos de 'ajustes fiscais' e de contingenciamentos orçamentários permanecem similares. $\mathrm{O}$ que se tem aprimorado são as formas de indução de governamentalidade neoliberal ${ }^{7}$, assim como as estratégias institucionais, as modalidades e os dispositivos para a focalização de políticas. Por exemplo, a per capitalização por riscos e vulnerabilidades, exaustivamente explorada nos mercados de seguros como forma de dimensionamento de preços para apólices, tem sido utilizada para definir e estabelecer critérios para o financiamento de estratégias programáticas de políticas sociais, sendo tal modalidade evidenciada adiante, na análise sobre a nova forma de financiamento da 'atenção primária no âmbito do SUS'.

Ainda em termos de governamentalidade neoliberal, um dos primados acerca das estratégias de focalização de políticas sociais advém do que Claus Offe ${ }^{17}$ definiu como seletividade estrutural do Estado, sob governança direcional de determinados grupos de interesses, que, naturalmente, tendem a priorizar as demandas sociais 'padronizáveis' e 'administráveis' nos termos de suas conveniências (por exemplo, contingenciamentos orçamentários para o financiamento de agiotagem rentista) e de suas prevenções (tal como controle e amortecimento de tensões sociais). A seletividade sistêmica e estrutural de demandas sociais 'convenientes' e 'administráveis' sob égide de uma 'democracia mínima' tende a produzir formas de 'indiferença estutural'18 a partir das políticas públicas, com a exclusão de demandas não 'padronizáveis' ou 'administráveis'. No extremo, até mesmo pode produzir o que alguns autores definem como uma das decorrências da necropolítica ${ }^{19}$ : a exterminação intencional de indivíduos e grupos populacionais considerados 'dispensáveis', de forma proativa (repressão) ou pela via do não reconhecimento de necessidades sociais imprescindíveis e, consequentemente, pela ausência de respostas governamentais compatíveis até mesmo para a sua mitigação.

Uma variação mais abrangente das estratégias de focalização para políticas sociais pode ser identificada nos últimos receituários de agências multilaterais e em recentes experiências de governos. Seriam mais propriamente estratégias de segmentação para políticas sociais com cobertura universal para determinadas estratégias programáticas, grupos de procedimentos ou 'cartas de serviços' (algo distinto do preceito de universalidade). No caso do setor de saúde, por exemplo, pode-se estabelecer a 'cobertura universal' para níveis assistenciais (como da APS), para procedimentos assistenciais (procedimentos de prevenção 
coletiva, como vacinações, de alto custo, como transplantes etc.) ou para 'cartas de serviços', com estratificação de demandas e com alternativas complementares de mercado para a maioria da população empregada ${ }^{20}$.

No campo da saúde, há muitas proposições de estratégias institucionais compatíveis com os termos de segmentação com 'cobertura universal' (como o 'pluralismo estruturado'21 e outras), assim como experiências de implementação em sistemas nacionais de saúde (o caso da Colômbia é pioneiro na América Latina).

O que se denota, a partir de processos e de resultados das experiências internacionais com segmentação de 'coberturas universais' para determinados serviços públicos, é que tal disposição não pode ser dissociada da racionalidade utilitária referida anteriormente ao neoliberalismo. De início, porque geralmente têm ocorrido combinações de estratégias governamentais de segmentação e de focalização dos recursos e políticas sociais, ficando difícil distinguir as particularidades e as interveniências. Também, porque a adoção de estratégias de segmentação com 'coberturas universais', embora possa ter alcançado resultados e obtido impactos sobre determinados perfis epidemiológicos em alguns países do Hemisfério Norte, não alterou substancialmente as margens de contingenciamento de recursos públicos, tampouco os termos de 'eficiência' para além das medidas restritas de 'contenções orçamentárias'. As experiências de implementação de estratégias para segmentações com 'coberturas universais' em países de capitalismo periférico, como o citado caso da Colômbia, não apresentaram resultados de melhor gestão orçamentária, uma vez que a 'economia' de recursos de tal 'eficiência alocativa' têm sido incrementalmente sequestrada pelas dinâmicas de agiotagem do mercado financeiro ${ }^{22}$; sequer apresentaram resultados de melhoria de iniquidades de acessibilidade e de impactos epidemiológicos.

Acerca da contraparte dialética, políticas sociais e estratégias institucionais visando melhor equidade redistributiva, haveria muito o que reportar e distinguir sobre as premissas filosóficas, a constituição histórica de sentido e suas derivações em termos de estratégias governamentais para políticas públicas. Por exemplo, poderiam ser analisadas desde as formulações originais de economia política redistributiva a partir da década de $1930^{23}$ até o advento e experiências internacionais do chamado Welfare State em países setentrionais (em meados do século XX). Ademais, poderiam ser analisadas as distintas experiências de políticas e estratégias governamentais afins (parciais, setoriais, incrementais), ocorridas e decorridas em países meridionais de capitalismo periférico. Muitas dessas abordagens abrangentes precedem e poderiam ser contextualizadas como significativas para a concepção, a constituição original e a prescrição normativa do SUS brasileiro. Entretanto, tal intento estenderia por demais o presente texto, que requer atenção para versar sobre 'focalização'.

\section{A Atenção Primária à Saúde como um consenso internacional genérico, polimorfo e o seu viés utilitário e tecnocrático}

Sem delongas sobre os primórdios da APS, desde formulações modelares (Informe Dawson, Modelagem de Leavell \& Clark etc.) até experiências governamentais (National Health System - NHS etc.), a partir da década de $1970^{24}$, o conceito genérico acerca de tal estratégia institucional tornou-se uma espécie de consenso internacional (consagrado inicialmente na Conferência de Alma-Ata), todavia, por entendimentos, interesses, motivações, racionalidades e propósitos diversos. Mesmo assim e desde então, tem havido contradições e contendas sobre as disposições estratégicas da APS como um nível de seletividade focalizada (APS seletiva, 'atenção primitiva'25) ou como uma base hierarquizada potencialmente 
e tendencialmente equitativa para sistemas universais de saúde. Evidentemente, tais discordâncias também implicam distintas estratégias institucionais e modos de integração sistêmica para a APS. Todavia, não houve muita celeuma acerca das postulações específicas, programáticas e tecnológicas de cuidados, para a organização, os processamentos, a gestão e a produção de serviços de APS em âmbitos locais.

Até mesmo em subsistemas privados com fins lucrativos, passou-se a valorizar estratégias similares (não propriamente a APS) com serviços domiciliares (Home Care) e ambulatoriais de melhor resolubilidade para demandas que requerem intervenções clínicas com menor densidade tecnológica e, principalmente, com a triagem padronizada por protocolos de algoritmos e por autorizações prévias (gatekeeping) para referenciamentos mais especializados e apoios diagnósticos e terapêuticos. Obviamente, a racionalidade utilitária e o propósito primordial da adoção de tais estratégias primam pela diminuição de custos e gastos evitáveis, a melhor eficiência em termos de lucros. Convém denotar que, se nos países do Hemisfério Norte as estratégias de Home Care têm mais a ver com procedimentos de média complexidade para âmbitos domiciliares, aqui no Brasil, existem diversos exemplos de 'planos de saúde' com ofertas de 'cuidados domiciliares' consubstanciados em procedimentos típicos da APS (algumas ofertas, inclusive, com programações intituladas explicitamente de Home Cares).

A APS e as estratégias congêneres conformam uma espécie de consenso internacional genérico em que cabem distintas motivações, interesses, propósitos, decorrentes estratégias institucionais e modalidades organizativas, sejam elas focalizadas, segmentadas ou integradas em sistemas universais. Assim, não basta a reiteração de alinhamento ao consenso genérico, mas é preciso distinguir e discernir sobre de que tipo de APS estamos tratando e, principalmente, conforme antecipado, em qual o contexto social, político e econômico se insere.
A partir da década de 1990, ocorreram a renovação e a disseminação de teorias sistêmicas (Luhmann e outros) ${ }^{\mathbf{2 6}}$ e da complexidade (Morin e outros) ${ }^{27}$, que serviram de substrato e referência para a reformulação de conceitos logísticos aplicáveis em termos de estratégias institucionais para políticas sociais. Por exemplo, as modelagens hierarquizadas passaram a ser reconhecidas em arquiteturas reticulares de poliarquia ${ }^{\mathbf{2 8}}$ (redes com verticalidades, horizontalidades, transversalidades, tramas etc.). No campo das políticas de saúde, tais reformulações repercutiram notadamente na redefinição de arquiteturas sistêmicas, por exemplo, as estratégias institucionais de APS passaram a ser reconfiguradas como umas das 'portas de entradas', dos pontos de Atenção de múltiplas e sinérgicas redes de cuidado, particularmente, como instâncias primordiais para as coordenações de fluxos e referenciamentos ('linhas de cuidado', itinerários terapêuticos etc. $)^{29}$.

Também a partir da década de 1990, pesquisas e estudos internacionais (com ênfase no protagonismo, coordenação e publicações da Dra. Bárbara Starfield ${ }^{\mathbf{3 0}}$ ) confluíram para produzir evidências empíricas acerca da melhor efetividade de (sub)sistemas de saúde com a APS estruturada e funcional a partir de determinados atributos, tais como: o primeiro contato; a longitudinalidade, a integralidade e a coordenação do cuidado; a focalização em famílias; a orientação comunitária e a competência cultural. A partir desses trabalhos, ocorreu a formulação de metodologias e de instrumentos para a avaliação sistêmica e normativa da APS (PCATools e outros). Tais conhecimentos, metodologias e tecnologias produziram uma significativa reciclagem no modo de organização das estratégias de APS e, consequentemente, reformulações tecnológicas e tecnocráticas compatíveis e aplicáveis tanto em diretivas estratégicas de focalização e de segmentação como de integração em sistemas universais de Atenção Integral à Saúde.

Outro fenômeno concomitante e correlato tem a ver com (re)formulação dos conceitos 
de gestão e governança clínica. A adoção de premissas de racionalidade sistêmica e complexa da contemporaneidade produziu reformulações significativas dos critérios e termos logísticos para as tomadas de decisões clínicas, para a reordenação de fluxos e itinerários de manejo clínico (de apoio diagnóstico e terapêutico, de cuidado, de reabilitação). A ênfase nos propósitos de economia de escopo e de escala também proporcionaram reformulações significativas nos critérios e termos de eficiência alocativa e custo-efetividade. Sendo repetitivo, reformulações compatíveis e aplicáveis tanto em diretivas estratégicas de focalização e de segmentação quanto de integração em sistemas universais de Atenção Integral à Saúde.

Uma das condições imprescindíveis para disseminação de inovações tecnológicas e para o desenvolvimento de seus processos de (re)produção requer a constituição de comunidades de práxis e/ou de práticas correlatas e afins. As comunidades de práxis tendem a priorizar a racionalidade e a competência estratégica, buscam incorporar e experimentar as inovações tecnológicas e tecnocráticas, entretanto, coproduzindo dinâmicas críticas e criativas para as suas contextualizações, alterações e autoproduções (autopoieses, na perspectiva sistêmica). Algumas das comunidades de práticas tendem a priorizar a disseminação de doutrinas tecnocráticas e as adaptações de ortodoxias modelares; nesses casos, conforma-se também um campo mais fértil para a preponderância de racionalidade teleológica e competência instrumental, para a colonização de pendores utilitaristas. Em se tratando de comunidades afeitas às estratégias de APS no mundo e, particularmente, no Brasil, podem-se identificar ambos os perfis, muitas vezes em disputa ideológica, política e (por que não escrever?) paradigmática (ou, em muitos casos, paradogmática).

Também no Brasil, vicejam especialistas da APS com postura mais tecnocrática e corporativa, com pretensões de combinar verticalidades utilitárias e teleológicas para reduzir e acondicionar aspectos logísticos e instrumentais (dos processos e práticas de gestão e atuação clínica) aos termos restritos de eficácia baseada em 'evidências clínicas' e orientada por protocolos e algoritmos decisionais de caráter estritamente sistêmico. Essa racionalidade protocolar de caráter estritamente sistêmico tende a ser mais facilmente regulada e integrada extrinsecamente por políticas econômicas, pelos imperativos de eficiência alocativa e de austeridade preconizados pela agenda de reformas neoliberais. Tal postura tecnocrática, preponderantemente biomédica e regulada por viés econocrático, despreza hermenêuticas críticas, discussões teóricas e questionamentos metodológicos, buscando amparo em uma doutrina 'pragmática' pela qual se cultuam 'caixas de ferramentas', normativas de adestramento, competências instrumentais e comportamento regrados.

No apelo utilitário dessas doutrinas tecnocráticas da APS, de seus 'tecnocratas orgânicos' (perdoe-me, Gramsci) ${ }^{31}$, importar e incorporar estratégias institucionais entre contextos distintos e diversos (como do Hemisfério Norte para o Sul) requer mais adaptações e adestramentos do que práxis de contextualização, inovações e mudanças autóctones e modos de gestão participativa. Se a conjuntura for propensa e favorável aos pendores autoritários de governo, facilmente as incorporações estratégicas (administrativas, programáticas) e tecnocráticas, suas adaptações e os decorrentes adestramentos tendem a ser verticalizados a partir de imposições e da utilização de recursos de poder administrativo e político.

É notório que, atualmente, alguns dos arautos e expoentes da doutrina tecnocrática da APS ocupam cargos-chave na direção de entidades representativas de especialidades profissionais e na gestão governamental, inclusive, do Ministério da Saúde (MS). Provém dessa vertente, a nova formulação estratégica para a adscrição e o financiamento da APS-SUS. 


\section{Do contexto utilitário e distópico a uma conjuntura de autoritarismo e disrupção}

A partir de 2016, o governo brasileiro operou um incremento radical no seu progressivo alinhamento e subserviência para com a agenda de reformas neoliberais. Após um golpe parlamentar e do lawfare ${ }^{32}$ capitaneados por corporações autoritárias da sociedade política e civil, o governo Temer realizou uma reforma constitucional visando à colateralização e à precarização de contratos e vínculos trabalhistas; além disso, estabeleceu um 'teto' para os 'gastos primários', com lastro orçamentário de duas décadas para o incremento de garantia de usufruto da agiotagem rentista (EC-95/2016). Tratou-se do início de reformas genoestruturais, com 'estado de sítio' fiscal e orçamentário, que antecederam desdobramentos e derivações específicas, como o advento de estratégias governamentais de focalização e segmentação para políticas sociais.

A subsequente eleição de Jair Bolsonaro produziu uma conjuntura disruptiva e instável. Uma conjuntura contemporânea que, como em outras fases históricas de crises superestruturais ${ }^{33}$ no Brasil, deriva do esgotamento para mais um ciclo condominial (governabilidade de coalizão, dependente do mercado da pequena política) e de reaparecimento do tragicômico personagem 'redentor da moralidade pública' (assim como, Jânio Quadros e Collor de Mello), em parte como a imposição distópica de um novo bloco histórico, dirigido por plutocracia rentista. A alternativa escolhida para a continuidade de condução governamental coercitiva em uma transição regressiva (de direitos políticos e civis, de políticas públicas e sociais) é uma espécie de governo miliciano 'ultraliberal', afeito e propenso às insinuações e experimentações neofascistas.

Conforme a história demonstra em repetidas 'farsas ou tragédias', o caráter autoritário de governos tem sido atrativo para imposições tecnocráticas, verticais e abruptas. Imposições que podem ocorrer de modo direto, por coações e chantagens ou por modos indiretos, como 'premiações' por adesão (e consequentes punições pela negativa). Entretanto, existiram imposições tecnocráticas sob regimes autoritários estáveis e proativos, cujas decorrências tenderam para consolidações parciais de determinadas estratégias institucionais; e houve imposições tecnocráticas em regimes autoritários instáveis e disruptivos, cujas decorrências tenderam mais para a barbárie ${ }^{34}$.

Reiterando algo afirmado anteriormente, assim como são imprescindíveis as contextualizações (históricas, conceituais, sociais, políticas, econômicas etc.), também não podem ser desconsideradas ou menosprezadas as conjunturas políticas em que ocorrem e decorrem determinadas reformas políticas e estratégicas, sejam genoestruturais ou fenoestruturais.

Em termos de reformas genoestruturais, $o$ governo Bolsonaro e o Congresso Nacional já aprovaram um significativo desmonte no regime previdenciário e alinham agora o encaminhamento de desmontes administrativos e de alterações no regime tributário, concomitantes com uma ofensiva incremental para privatizações, terceirizações e agenciamentos empresariais de estabelecimentos e serviços públicos.

Além das iniciativas fenoestruturais de disrupções e de desmontes da institucionalidade estatal, a partir de 2019, alguns dos setores administrativos do governo Bolsonaro iniciaram as suas proposições e imposições tecnocráticas em termos específicos de estratégias institucionais para focalização e segmentação de recursos públicos e de políticas sociais. É o caso da nova estratégia governamental para o financiamento da APS-SUS, sumariamente analisada adiante.

De início, convém destacar que a referida proposição estratégica (de teor administrativo e programático), descrita na Portaria Ministerial $\mathrm{n}^{\mathrm{o}}$ 2.979/201919, tende mais para os propósitos de focalização de recursos e demandas da APS/ SUS do que para a perspectiva de segmentação de sua cobertura universal, embora possa haver compatibilizações e combinações adiante (o que dependeria de sinergia para com outras estratégias institucionais mais abrangentes). 
Tal assertiva deriva da constatação de que os termos dessa estratégia específica estão focalizados no modo de adscrição dos serviços de APS-SUS, com indução de sua modificação pela via de financiamento de custeio, como também na indução de regramento e conformidade do trabalho profissional correlato, com indução pela via de 'pagamento por desempenho'.

A principal modificação induzida dispõe sobre o fim da adscrição territorial e populacional de Atenção Integral à Saúde sob a responsabilidade das equipes da APS, com o advento da adscrição de clientelas (conforme ocorre em países do Hemisfério Norte) cadastrados nos serviços e estratificados em função de suas 'vulnerabilidades socioeconômicas'. Na portaria ministerial, tal modificação encontra-se sintetizada sob a terminologia normativa e instrumental de 'capitação ponderada'.

\section{Principais termos logísticos da nova estratégia para a adscrição e o financiamento da Atenção Primária do Sistema Único de Saúde}

A 'capitação ponderada' da nova estratégia consubstancia-se pela via de um cálculo e pelo aporte de 'incentivos financeiros' que dependem da população cadastrada pelas equipes de Saúde da Família (eSF) e de Atenção Primária (eAP); da estratificação dessa população, a partir de critérios de 'vulnerabilidade socioeconômica' e de 'perfil demográfico' por faixas etárias; da classificação específica de porte populacional e de situação (urbana, rural próxima ou remota) dos locais em que as referidas equipes atuam. No documento, há uma afirmação enfática de que a definição preponderante dos 'incentivos financeiros' depende do 'peso por pessoa cadastrada', destacados os critérios de estratificação referidos anteriormente.

De acordo com a normativa citada, referidos 'incentivos financeiros' de custeio só deverão ser transferidos aos municípios que tiverem cadastrado a totalidade de sua população. Os fatores para a ponderação alocativa individualizada estabelecem pesos maiores ( $+30 \%$ per capita) para pessoas em situação de vulnerabilidade socioeconômica (beneficiárias de programas como o Bolsa Família, ou com benefícios previdenciários de Prestação Continuada (BCP) e de até dois salários-mínimos mensais), pessoas com menos de 5 anos e mais de 65 anos (perfil demográfico); pesos ponderados que podem ser incrementados (para $45 \%$ ou $100 \%$ ) no caso de essas pessoas cadastradas habitarem em municípios classificados como 'intermediário adjacente' e 'rural adjacente' ( $+45 \%$ per capita) ou 'intermediário remoto' e 'rural remoto' $(+100 \%$ per capita). Os fatores de ponderação não têm caráter cumulativo, ou seja, nos casos em que a pessoa cadastrada for enquadrada em mais de um estrato incremental (vulnerabilidade socioeconômica ou perfil demográfico), o peso ponderado deverá ser considerado uma única vez.

Os indivíduos cadastrados pelas equipes de APS que não estiverem contemplados em nenhum dos critérios de per capitalização incremental deverão estar estratificados como 'peso 1', ou seja, constarão nos cálculos de transferência basal. Assim, o cálculo do valor total a ser repassado para APS dos municípios levará em conta a multiplicação das pontuações de valores per capita a partir dos critérios preestabelecidos de estratificação.

Outra ênfase da referida portaria ministerial enfoca o propósito de incrementos nas transferências de custeio como premiação por 'desempenho' das equipes de APS-SUS, a ser dimensionado em 'metas' e classificado por 'tipos de equipes: uma modalidade para eSF e duas modalidades para eAP (respectivamente de 20 horas e 30 horas semanais). As referidas 'metas' estão caracterizadas pelo anacrônico escopo donabediano de 'processo' e 'resultados' (uma vez que o componente de 'estruturas' depende do próprio aporte de transferências federais e os 'recursos humanos' já estão contemplados pela variável dos 'tipos de equipes'); mais especificamente, processos e resultados 'intermediários' do trabalho das 
equipes (outputs), além de 'resultados em saúde' (outcomes) e 'resultados globais da APS' (definidos e dimensionados pelo referido dispositivo PCATools). Os indicadores de "desempenho" deverão ser definidos e atualizados na Comissão Intergestores Tripartite (CIT), e os pagamentos correspondentes só deverão ser efetivados se forem alcançados resultados potenciais de $100 \%$ pelas equipes de APS dos municípios. Os cálculos municipais deverão corresponder ao somatório dos resultados obtidos pelas equipes.

O MS divulgou uma projeção inicial para dimensionar perdas e ganhos municipais em termos do custeio da APS-SUS, a partir da nova ordenação e, especificamente, em relação aos valores recebidos em 2019: 68,2\% municípios obteriam acréscimos; aproximadamente $14 \%$ dos municípios não teriam alterações 'significativas'; e 17,8\% dos municípios teriam decréscimos. Tal projeção foi repercutida pelo Conselho Nacional de Secretarias Municipais de Saúde (Conasems) ${ }^{35}$ como a principal justificativa em defesa das 'vantagens' de transição para o novo modelo. Ainda não foram divulgadas comparações retrospectivas com séries históricas de médio ou longo prazo, tampouco projeções prospectivas levando em conta os contingenciamentos orçamentários para o orçamento federal (termos da EC-95) e, particularmente, para os imprescindíveis rearranjos proporcionais entre os valores de custeio da APS e da assistência especializada.

\section{Focalização disfarçada em equidade, segmentação disfarçada em integralidade, utilitarismo tecnocrático tendencialmente disruptivo do Sistema Único de Saúde}

O principal argumento de defesa da nova forma de financiamento da APS-SUS, divulgado em nota pelo Conasems ${ }^{35}$, ilustra um cálculo exemplar do senso de 'governamentalidade' utilitarista, sobre as razões e modos de indução a comportamentos regrados e de introjeções autogovernamentais, ${ }^{7}$. No campo da gestão governamental, naturalmente, há uma propensão ao utilitarismo de curto prazo, muitas vezes confundido com 'pragmatismo', principalmente, entre aqueles governantes com alcance de olhar e de atuação adscritos aos horizontes de mandatos eleitorais, com cegueira estratégica para perspectivas de políticas de Estado projetadas em maiores abrangências ou alcances tendenciais. Em tal delimitação de horizonte, muitas vezes, o sentido de 'eficiência' fica reduzido às equações de custos orçamentários sobre benefícios eleitorais, aos jogos táticos de compensações focalizadas ('premiações' por adesão etc.). Para tal 'senso prático', não é muito difícil oferecer aparentes aditivos no 'varejo' e curto prazo, enquanto se realizam subtrações e deformações de políticas e estratégias institucionais no 'atacado'.

Nos últimos anos, da parte de muitos gestores governamentais, tem sido comum a defesa de racionalidades utilitárias, tais como a instituição do que alguns definem como 'padrões de integralidade', denominação tortuosa do que em outros países está definido mais precisamente como 'cartas de ofertas' de procedimentos e serviços, reguladas por perfis de necessidades e por padrões de consumo para insumos. Todavia, tal alusão reportada ao princípio constitucional de integralidade do SUS revela primordialmente o entendimento restrito sobre uma tensão normativa de valor ético social (um deve-ser que nunca se alcança, mas que tensiona continuamente por consubstanciações e aprimoramentos estratégicos) e sua redução a uma competência instrumental e um sentido utilitário de 'eficiência' orçamentária. Sentido de pragmatismo (auto)limitado e (auto)regulado por governamentalidade colonizada e subalterna.

Diga-se de passagem, dadas a grande concentração proporcional de recursos tributários no orçamento federal e a dependência 
de municípios e estados em relação às transferências federais de recursos financeiros, uma das características típicas do processo de implantação do SUS ao longo das últimas três décadas tem sido a adesão induzida às estratégias institucionais do MS pela via de governança (intergovernamental) de caráter procedimental. Esclarecido de outro modo, os termos de governança direcional geralmente estão preestabelecidos (pela política econômica de 'austeridade' e de contingenciamentos progressivos), restando aos governantes de políticas setoriais definir derivações direcionais correlatas, a partir de dinâmicas de governança limitadas aos modos de implantação e de condução para estratégias institucionais condizentes. No caso das instâncias e dinâmicas intergovernamentais de governança no setor de saúde, comumente, o MS estabelece as derivações direcionais em termos de estratégias institucionais (administrativas e programáticas) e opera ainda com estratégias de 'premiação por adesão' para os governos subnacionais. Com a inevitável e 'voluntária' adesão, as representações políticas dos Secretários de Saúde buscam discutir, estabelecer acordos, 'consensos' e pactuações nas Comissões Intergestores (principalmente na Tripartite), sobre os termos e os trâmites procedimentais para as referidas verticalidades estratégicas, conferindo a elas a aparência de autoridade federativa coordenada (quando ainda se trata de autoridade federativa dominante) ${ }^{\mathbf{3 6}}$.

Já decorreu tempo suficiente para a hegemonização de uma 'cultura institucional' e de um 'senso comum pragmático' na gestão intergovernamental de políticas de saúde no Brasil. Nas últimas três décadas, ocorreram avanços incrementais muito significativos para algumas estratégias institucionais sintônicas e sinérgicas ao SUS; atores governamentais, atuando nas Comissões Intergestores, dispuseram resistências e óbices perante tentativas de imposições verticais mais autoritárias (muitos são os exemplos); mas, também, instituiu-se a hegemonia de um pendor utilitarista dependente de táticas conjunturais de caráter meramente adaptativo. Alguns podem entender que esta é a natureza e a sina 'pragmática' de quaisquer processos de gestão institucional, o que pode ser delimitado em determinados continentes e perspectivas (administrativas, burocráticas e de racionalidade sistêmica autorregulada); entretanto, pode implicar a abdicação de disputas estratégicas substanciais.

Conforme argumentação prévia, a análise estratégica e situacional de contextos e conjunturas políticas deve ser concomitante e dialética com a apreciação de derivações estratégicas mais específicas, setoriais e programáticas. O Programa Previne Brasil não versa somente sobre uma nova programação financeira para a APS-SUS, a partir dele, busca-se importar, incorporar e implantar logísticas sistêmicas e tecnologias adotadas em outros países, com relativos sucessos, em um contexto diverso deles. Busca-se consolidar modos de integração sistêmica (auto)regulados pelos termos e propósitos 'ultraliberais', por isso mesmo, disruptivos para as políticas públicas de caráter redistributivo.

Seguramente, a ameaça disruptiva em curso não decorre da adoção de racionalidade instrumental ou dispositivos para a recomposição de financiamentos para as políticas públicas de saúde, a partir de critérios e pesos ponderados para alocação recursiva, inclusive, algo pertinente e necessário na perspectiva da produção de equidades e diminuição de iniquidades. De forma similar, não decorre da adoção de pagamentos e valores agregados, a partir de critérios para recomposição e valorização de trabalho profissional, algo pertinente e necessário na perspectiva de planos de cargos, carreiras e salários em qualquer política pública de abrangência nacional. As ameaças disruptivas decorrem do sentido contextual, da barbárie conjuntural e da direcionalidade estratégica que buscam focalizar e segmentar as estratégias institucionais primordiais ao SUS, destituindo-as do sentido de seus valores éticos sociais, notadamente de equidade e integralidade. 
A per capitalização alocativa a partir de cadastros individualizados (e não adscritos territorialmente) de clientelas da APS é comum em muitos países do Hemisfério Norte e Ocidental com sistemas de saúde universais, em sua maior parte, contando com serviços clínicos que orbitam na dependência de trabalho médico semiautônomo, especializado e contratado (ou seja, não de servidores públicos de carreira). Para quem conhece minimamente os condicionantes originais da matriz estratégica de tal modelagem (recomenda-se revisarem os fatos originários e as mediações políticas imprescindíveis para a garantia de viabilidade inicial do NHS inglês, sob a direção do Ministro Aneurin Bevan), não é difícil compreender e constatar que se tratou de iniciativa correta, contextualmente e conjunturalmente. Houve ênfase na incorporação de profissionais médicos fora da carreira de Estado, como também na liberdade de escolha e autonomia das clientelas (territorializadas em temos de responsabilidades sanitárias, mas não adscritas em termos de vinculações com profissionais e serviços clínicos). Ao longo de décadas, tal escolha foi sendo aprimorada, experimentada e adaptada em países de condições similares (países escandinavos, Canadá, Austrália etc.), produzindo não somente resultados efetivos (em integralidade complementar com outros subsistemas), mas também uma 'cultura institucional'. Em muitos dos países referidos, ocorreram inovações e mudanças em políticas públicas (não somente de saúde) e em experiências típicas de Welfare State, que se consolidaram incrementalmente, mesmo que parcialmente. Dados os contextos sociais e econômicos desses países, a per capitalização alocativa e a adscrição de clientelas na
APS não decorreram em focalizações (foco em denominadores populacionais de riscos, vulnerabilidades ou miserabilidades), contribuindo para organização e consolidação de universalidade e integralidade do cuidado; embora, depois do advento do neoliberalismo, ocorra uma tendência à segmentação de determinadas estratégias institucionais.

O caso brasileiro é historicamente distinto, assim como o seu contexto institucional, social e econômico. O surgimento tardio (em comparação aos exemplos anteriores) das tensões constitucionais do SUS no início da década de 1990 pode ser mais adequadamente caracterizado como um vetor setorial para pretensões políticas de 'bem-estar social'. Ainda assim, os princípios constituintes do SUS e suas respectivas diretrizes estratégicas devem ser considerados de modo ambivalente, sinérgico e interdependente.

Os valores éticos sociais estabelecidos para o SUS ensejam o reconhecimento de que há multideterminantes complexos e dialéticos para os processos de (re)produção de saúde e suas antíteses, que incidem desigualmente e iniquamente sobre indivíduos (singularidades), grupos (particularidades coletivas) e populações. Em suas diretrizes estratégicas, a seguridade social e o SUS preconizam a organização de sistemas institucionalizados de Atenção Integral à Saúde (figura 1), cujo sentido precípuo, enquanto configuração sistêmica (polity) e proatividade institucional para a produção de bens e serviços públicos (policy), requer coerência e compatibilidade contextual. No contexto normativo do SUS, as estratégias institucionais de focalização em singularidades (clínicas ou epidemiológicas) são incoerentes e incompatíveis 
Figura 1. Configuração sobre multideterminantes complexos, condições de desigualdades ou iniquidades e ocorrências de eventos pertinentes aos processos de (re)produção social de saúde, em relação a componentes sistêmicos e institucionais de Atenção Integral à Saúde, de acordo com os princípios e diretrizes estratégicas do SUS

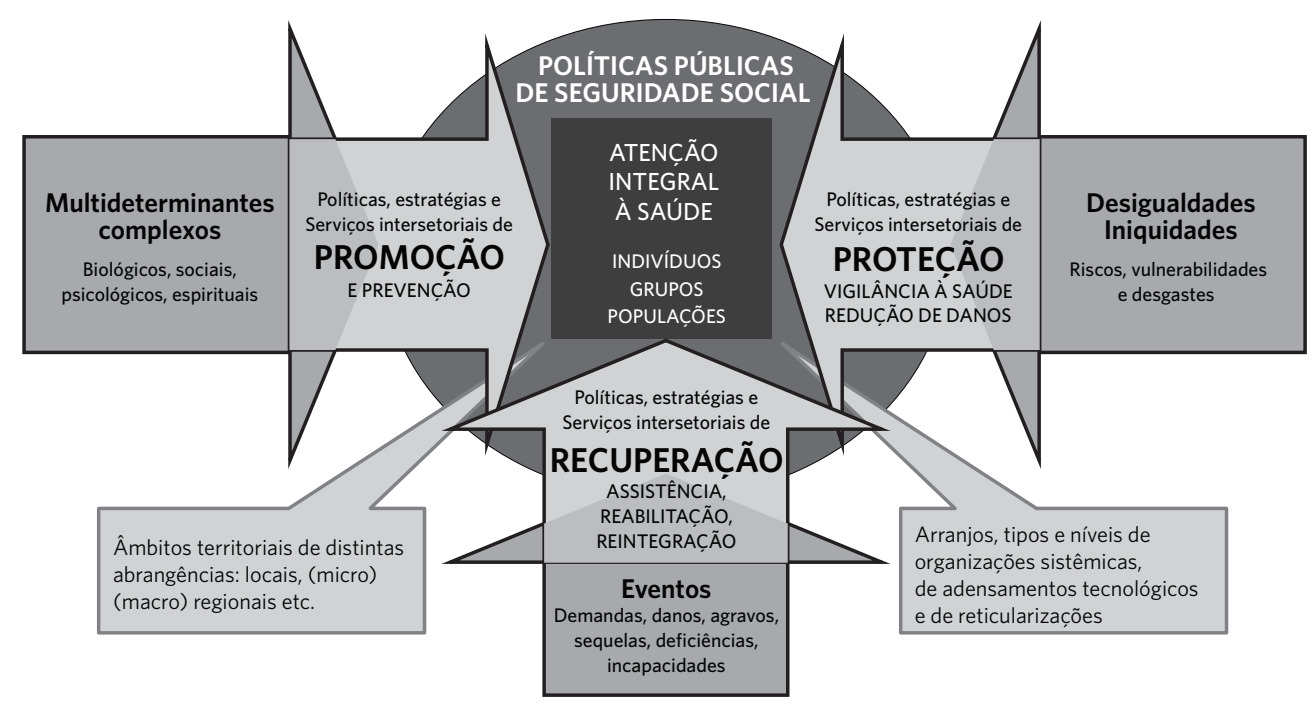

Fonte: Elaboração própria.

No decorrer do processo de implantação do SUS, sucessivas e adversas conjunturas políticas constrangeram os termos de sua viabilidade recursiva, dificultaram a implantação de estratégias inovadoras compatíveis e deformaram a sua pretensa arquitetura integral e reticular em arranjos dissociativos (para a seguridade social e para o próprio setor). Mesmo assim, algumas inovações estratégicas ocorreram e consubstanciaram modos de integração sistêmica, como exemplos: a Estratégia Saúde da Família, algumas das estratégias institucionais de saúde mental, de urgência e emergência, de vigilância em saúde etc.

No caso da Atenção Básica à Saúde (ABS) (versão SUS de APS), houve inovação significativa na implantação de uma modalidade de per capitalização para transferências federais (Piso Assistencial Básico - PAB, fixo e variável) vinculada à adscrição local de populações sob a responsabilidade de equipes multiprofissionais. Não se trata de adscrição de clientelas e demandas singulares ou particulares, mas da adscrição de âmbitos territoriais complexos, plurais, heterogêneos, iníquos e desiguais. Não se trata da adscrição de responsabilidades clínicas de serviços, mas de responsabilidades com a Atenção Integral à Saúde, que requerem arranjos sinérgicos, interdisciplinares e intersetoriais. Lamentavelmente, inovações congêneres não foram estendidas para a assistência especializada.

Além de prover as transferências financeiras para a ABS, o MS tendeu a direcionar, sob governança federativa, as suas principais estratégias administrativas e programáticas (Política Nacional de Atenção Básica - PNAB). Ao longo dos anos, o montante e a proporção de transferências federais para o custeio da ABS foram progressivamente incrementados, sendo que, inclusive, estabeleceram-se fatores de ponderação para as modalidades de PAB (portes populacionais, localização na Amazônia legal, tipos de equipes etc.). Todavia, persistiu um financiamento insuficiente como suporte recursivo para, além da expansão e aumento da cobertura populacional, potencializar 
mudanças mais substanciais do 'modelo de atenção', ainda sob o esquadro da assistência especializada.

Enquanto as Secretarias Estaduais de Saúde concentraram as suas estratégias institucionais na coordenação sistêmica e no controle normativo da ABS, coube aos municípios a maior responsabilidade na sua organização efetiva, financiamento, gestão local e prestação de serviços. Em grande medida, os gastos orçamentários municipais em saúde foram incrementados para além do piso estabelecido legalmente (15\%), em função da assunção de responsabilidades para o funcionamento e efetividade da ABS.

Em sua diversidade, o contexto institucional de gestões municipais tornou-se preponderante para a viabilidade administrativa e funcional da ABS. A maior parte de seus profissionais de saúde estão vinculados diretamente ou indiretamente como servidores públicos de governos municipais, sob diversos regimes contratuais. Mesmo iniciativas impactantes, como o provimento incrementado pelo Programa Mais Médicos (a partir de 2014), cuja vinculação contratual é de âmbito federal, não alteraram significativamente tal situação. Convém destacar que, no caso da força e dos processos de trabalho na ABS, de seus modos de vinculação contratual e perspectivas de campo profissional, há significativa distinção para com os exemplos supracitados e localizados em países do Hemisfério Norte e Ocidental.

A composição do pagamento de trabalho profissional com a agregação de valores dependentes de resultados (outputs, outcomes) objetiváveis, dimensionáveis e monitoráveis também é característica comum dos sistemas de saúde universais nos países mencionados. Os critérios, métodos e termos de composição e complementaridade para o pagamento de profissionais de saúde, assim como os indicadores correlatos de referência compensatória, geralmente estão reestabelecidos contratualmente. Trata-se, portanto, de uma pretensão e expectativa de eficiência alocativa regulada por eficácia contratual, geralmente individualizada (profissionais) e raramente particularizada (equipes). Culturas e contextos institucionais distintos dos processos de gestão do trabalho profissional na ABS brasileira.

Consideradas sumariamente algumas das premissas contextuais da ABS e do SUS, convém analisar os termos de coerência e compatibilidade para com a inovação estratégica veiculada pelo Programa Previne Brasil ${ }^{37}$, que determina a importação e a adaptação de modalidade de per capitalização alocativa individualizada e de adscrição de clientelas estratificadas por focalização.

A nova estratégia institucional não só é incoerente e incompatível com a ABS e o SUS como também induz a desconstituição valorativa de seu ethos social, desvirtuando o sentido polivalente e interdependente de universalidade com integralidade e equidade em âmbitos locais ${ }^{38}$. Deforma as diretrizes estratégicas para a Atenção Integral à Saúde, deslocando o seu âmbito de territórios sociais complexos para serviços; de necessidades populacionais complexas para demandas individualizadas, cadastradas e estratificadas por focalização de vulnerabilidade; subordina o sentido de gestão pública ao entorno tecnocrático de governança clínica; desloca a agregação de valores compensatórios para responsabilidades assumidas e para os processos e resultados de trabalho profissional, de um necessário contrato coletivo abrangente (planos de cargos, salários e carreiras de trabalhadores do SUS) para a particularidade de comportamentos regrados por 'desempenho' de equipes.

\section{Colaborador}

Miranda AS (0000-0001-8947-9676)* é responsável pela elaboração do manuscrito. 


\section{Referências}

1. Brasil. Ministério da Saúde. Portaria no 2.979 , de 12 de novembro de 2019. Institui o Programa Previne Brasil, que estabelece novo modelo de financiamento de custeio da Atenção Primária à Saúde no âmbito do Sistema Único de Saúde, por meio da alteração da Portaria de Consolidação nº 6/GM/MS, de 28 de setembro de 2017. Diário Oficial da União [internet]. 13 Nov 2019. [acesso em 2019 nov 20]. Disponível em: https://www.in.gov.br/en/web/dou/-/portaria-n-2.979-de-12-de-novembro-de-2019-227652180.

2. Habermas J. Mudança estrutural da esfera pública. Rio de Janeiro: Tempo Brasileiro; 2003. 397 p.

3. Medeiros M. Princípios de justiça na alocação de recursos em Saúde. [internet]. Rio de Janeiro: IPEA; 1999. [acesso em 2019 nov 22]. Disponível em: http:// repositorio.ipea.gov.br/bitstream/11058/2855/1/ td_0687.pdf.

4. Polanyi K. La gran transformación: critica del liberalismo económico. Madri: Virus Editorial; 2016.528 p.

5. Osborne R. Filosofia para principiantes. Rio de Janeiro: Objetiva; 1998. 192 p.

6. Habermas J. Teoría da la Acción Comunicativa: racionalidad de la acción y racionalización social. Madrid: Taurus Humanidades; 1987.

7. Foucault M. Sécurité, territoire, population: cours au Collège de France,1977-1978. Paris: Seuil; 2004. 448 p.

8. Dardot P, Lavall C. A nova razão do mundo. Ensaio sobre a sociedade neoliberal. São Paulo: Boitempo Editorial; 2016. 179 p.

9. Pereira JD, Sousa SSS, Patriota LM. Políticas sociais no contexto neoliberal: focalização e desmonte dos direitos. Qual. Rev. Eletrônica. [internet]. 2006 [acesso em 2020 ago 24]; 5(3):1-14. Disponível em: http://revista.uepb.edu.br/index.php/qualitas/article/viewFile/64/56.
10. Marsiglia RMG, Silveira C, Carneiro Júnior N. Políticas sociais: desigualdade, universalidade e focalização na saúde no Brasil. Saúde Soc. [internet]. 2005 [acesso em 2020 ago 24]; 14(2):69-76. Disponível em: https://www.scielosp.org/pdf/sausoc/2005.v14n2/69$76 /$ pt.

11. Kerstenetzky CL. Políticas Sociais: focalização ou universalização? Rev. Econ. Polit. [internet]. 2006 [acesso em 2020 ago 24]; 26(4):564-574. Disponível em: http://www.scielo.br/scielo.php?script=sci arttext\&pid=S0101-31572006000400006\&lng=en\& nrm=iso.

12. Dowbor L. A era do capital improdutivo. Por que oito famílias tem mais riqueza do que a metade da população do mundo? São Paulo: Autonomia Literária; 2017. 313 p.

13. Miranda AS. Institucionalidades jurídicas e administrativas de estabelecimentos de saúde nas regiões do Brasil [internet]. São Paulo: Novos Caminhos; 2017. 114 p. [acesso em 2019 nov 22]. Disponível em: https:// www.resbr.net.br/wp-content/uploads/2017/04/Novos_Caminhos_16.pdf.

14. Santos B. A crítica da governação neoliberal: o Fórum Social Mundial como políticae legalidade cosmopolita subalterna. Rev. Crit. Cienc. Soc. 2005; 72:7-44.

15. Teixeira RV. Uma crítica da concepção de política social do Banco Mundial na cena contemporânea. Serv. Soc. Soc. [internet]. 2010 [acesso em 2020 ago 24]; 104:650-680. Disponível em: http://www. scielo.br/scielo.php?script=sci_arttext\&pid=S0101$-66282010000400005 \& \operatorname{lng}=\mathrm{en} \& \mathrm{nrm}=$ iso.

16. Gobetti SW, Amado AM. Ajuste fiscal no Brasil: algumas considerações de caráter pós-keynesian. Rev. Econ. Polit. [internet]. 2011 [acesso em 2019 nov 24]; 31(1):139-159. Disponível em: https://doi.org/10.1590/ S0101-31572011000100007.

17. Offe C. Capitalismo desorganizado. 2. ed. São Paulo. Brasiliense; 1994. 322 p. 
18. Cohn G. A Sociologia e o novo padrão civilizatório. In: Barreira C, organizador. A Sociologia no Tempo. São Paulo: Cortez; 2003. p. 41-92.

19. Mbembe A. Necropolítica. São Paulo: N1 Edições; 2018. $80 \mathrm{p}$.

20. Mendes EV. Os grandes dilemas do SUS. Salvador: Casa da Qualidade Editora; 2001. 167 p.

21. Londoño JL, Frenk J. Pluralismo estructurado: Hacia un modelo innovador para la reforma de los sistemas de salud en América Latina. Washington: Banco Interamericano de Desarrollo; 1997. 32 p.

22. Rezende FC. O dilema do controle e a falha seqüencial nas reformas gerenciais. RSP. 2002; 53(3):53-77.

23. Lima NT, Fonseca CMO, Hochman G. A Saúde na construção do Estado nacional no Brasil: Reforma Sanitária em perspectiva histórica. In: Lima NT, Gerschman S, Edler FC, et al. Saúde e Democracia. História e perspectivas do SUS. Rio de Janeiro: Fiocruz; 2005. p. 27-58.

24. Novaes HM. Ações integradas nos Sistemas Locais de Saúde: análise conceitual e apreciação de programas selecionados na América Latina. São Paulo: Livraria Pioneira; 1990. 202 p.

25. Testa M. Pensar em Saúde. Porto Alegre: Artes Médicas; 1992.226 p.

26. Luhmann N, De Georgi R. Teoría de la sociedad. Guadalajara: Universidad de Guadalajara; 1993. 104 p.

27. Morin E. Ciência com consciência. Rio de Janeiro: Bertrand; 2000. 350 p.

28. Dahl RA. Sobre a democracia. Brasília, DF: UNB; 2009. $232 \mathrm{p}$.

29. Mendes EV. As redes de atenção à saúde. Brasília, DF: Organização Pan-Americana da Saúde; 2011. 549 p.

30. Starfield B. Atenção Primária: equilíbrio entre necessidades de saúde, serviços e tecnologia. Brasília, DF: Ministério da Saúde/Unesco; 2002. 726 p.
31. Gramsci A. Cartas do cárcere. Antologia [internet]. Galiza: Estaleiro Editora; 2011. 439 p. [acesso em 2019 nov 24]. Disponível em: https://www.yumpu.com/ pt/document/read/14553716/cartas-do-carcere-estaleiro-editora.

32. Casara RRR. Estado Pós-Democrático, Neo-Obscurantismo e Gestão Dos Indesejáveis. Rio de Janeiro: Civilização Brasileira; 2017. 240 p.

33. Coutinho CN. Gramsci: um estudo sobre o seu pensamento político. Rio de Janeiro: Civilização Brasileira; 1999. 202 p.

34. Souza J. A elite do atraso da escravidão ao Lava-Jato. Rio de Janeiro: Leya; 2017. 240 p.

35. Conselho Nacional de Secretarias Municipais de Saúde. Novo modelo de financiamento de custeios da Atenção Primária à Saúde [internet]. Brasília, DF: CONASEMS; 2019. [acesso em 2019 nov 18]. Disponível em: https://www.conasems.org.br/novo-modelo-de-financiamento-da-atencao-basica-e-lancado-no-palacio-do-planalto/.

36. Wright DS. Federalism, Intergovernmental Relations, and Intergovernmental Management. Historical Reflections and Conceptual Comparisons. PAR. 1990; 50(2):168-178.

37. Harzheim E. Previne Brasil: bases da reforma da Atenção Primária à Saúde. Ciênc. Saúde Colet. 2020; 25(4):1189-1196.

38. Miranda AS. Programa "Médicos pelo Brasil", simulacro reciclado e agenciamento empresarial [internet]. [Local desconhecido]: Carta Maior; 2019. [acesso em 2020 ago 24]. Disponível em: https://www.cartamaior. com.br/?/Editoria/Saude/Programa-Medicos-pelo-Brasil-simulacro-reciclado-e-agenciamento-empresarial-/43/44908.

\footnotetext{
Recebido em 28/11/2019

Aprovado em 28/08/2020

Conflito de interesses: inexistente

Suporte financeiro: não houve
} 